\title{
Isolation and growth characteristics of adult human tendon fibroblasts
}

\author{
M D CHARD, J K WRIGHT, AND B L HAZLEMAN \\ From the Rheumatology Research Unit, Addenbrooke's Hospital, Hills Road, Cambridge
}

SUMmaRY An explant method for the isolation of fibroblasts from adult human tendon is described. Cells were successfully isolated from 22 out of 27 common biceps tendons obtained from cadaveric donors (age range 11-83 years). The fibroblasts could be maintained in culture using standard methods and morphologically resembled those of synovial rather than dermal origin. Growth characteristics of 12 cell lines were assessed by deoxyribose nucleic acid (DNA) synthesis using $\left[{ }^{3} \mathrm{H}\right]$ thymidine incorporation in response to stimulation by fetal calf serum. Cells obtained separately from superficial and deep parts of the tendons produced almost identical responses. No significant reduction in growth response with increasing age was found when related to the age of the donor. Therefore this study did not show any age related defect in the short term tendon fibroblast replicative responses to serum.

Key words: in vitro, DNA synthesis.

Tendinous lesions are common, but their nature and any possible predisposing factors are not well understood. They occur in middle life frequently after only minor, if any, injury. The extent to which this reflects age related changes in tendon tissue is uncertain. Thus investigation of the functions of tendon tissue could be of central importance in understanding the aetiopathology of such lesions. One approach to this problem is the study and characterisation of human tendon fibroblasts in vitro.

Organ culture of tendon of both avian and mammalian origin has shown how tendon fibroblasts respond to injury. ${ }^{1-4}$ Culture of cells derived from animal tendon has provided information on growth, metabolism, and collagen formation. ${ }^{5-9}$ Interspecies differences occur, however, and therefore the relevance of these studies to human tendon must be open to question. Although some work has been carried out on human tendon fibroblasts of fetal origin, this has uncertain relevance to aging tendon. ${ }^{10}$

Differences exist between fibroblasts of different tissue origin, ${ }^{11-14}$ and therefore investigation of adult human tendon fibroblasts would have more relevance than making inferences from work on

\footnotetext{
Accepted for publication 4 December 1986.

Correspondence to Dr M D Chard, Rheumatology Research Unit, Level E6, Addenbrooke's Hospital, Hills Road, Cambridge CB2 2QQ.
}

other tissues such as skin. It is desirable to investigate adult human tendon fibroblasts directly. It was thought that the culture of adult human tendon fibroblasts would be very difficult to achieve because of the differentiated appearance of cells on histology ${ }^{15}$ and the traditional concept of tendon healing by adhesion alone. ${ }^{16-19}$ Recent work in animals has shown that tendon has the capacity for intrinsic repair. ${ }^{1-4} 20-23$ This process involves migration, replication, and collagen formation by tendon fibroblasts.

These studies have raised the possibility that fibroblasts could be isolated from adult human tendon and maintained in vitro. The present study was carried out to investigate this possibility and, if successful, to assess the growth characteristics of tendon fibroblasts.

\section{Materials and methods}

IS OLATION

Adult human tendon was obtained from fresh cadavers within a short time of death $(<12 \mathrm{~h})$. The common biceps tendon was chosen for ease of aseptic removal and being unsheathed does not have a covering of synovial type fibroblasts which could have been a source of contaminating cells.

After being washed three times in Hanks's balanced salt solution (HBSS) buffered with $20 \mathrm{mM}$ HEPES ( $N$-2-hydroxyethylpiperazine- $N^{\prime}-2$ - 
ethanesulphonic acid; Gibco, Paisley, Scotland) all fat and loose tissue surrounding the tendon was carefully dissected away and fragments 1-3 mm thick and up to $5 \mathrm{~mm}$ in length were cut from it.

Fragments were placed in groups in $50 \mathrm{~mm}$ tissue culture grade plastic Petri dishes (Sterilin, Teddington, England). Each group was covered with a $10 \mathrm{~mm}$ diameter circular sterile glass coverslip held in place with a spot of sterile silicone grease. Four coverslips were used per dish. Three millilitres of Dulbecco's modification of Eagle's medium (DMEM) supplemented with $20 \mathrm{mM}$ HEPES, $10 \%$ fetal calf serum (FCS), and antibiotics (Gibco, Paisley, Scotland) was added to each dish. The cultures were then incubated at $37^{\circ} \mathrm{C}$ in a humidified atmosphere. The medium was changed weekly. The use of coverslips increased the area of tendon to surface contact, thus encouraging fibroblast outgrowth. ${ }^{24}$

Once adequate cell migration and replication had occurred the coverslips were inverted and the medium and explants were carefully removed. The fibroblasts were washed with calcium and magnesium free HBSS and removed from the dish and coverslips by incubation with $0.25 \%$ trypsin and $0.02 \%$ ethylenediaminetetra-acetic acid in calcium and magnesium free HBSS (Flow Laboratories, Irvine, Scotland). The cells were transferred to $25 \mathrm{~cm}^{2}$ plastic culture flasks (Nunc, Gibco, Irvine, Scotland) and maintained in monolayer in DMEM supplemented with $20 \mathrm{mM}$ HEPES, $10 \%$ FCS, and antibiotics.

Tissue fragments from the surface of the tendon were cultured separately from those from within it as a previous report has suggested that the superficial cells are most active in tendon repair. ${ }^{25}$

GROWTH EXPERIMENTS

A representative sample of 12 tendon fibroblast lines was used from an age range of 11 to 83 years. Growth was assessed by DNA synthesis using $\left[{ }^{3} \mathrm{H}\right]$ thymidine incorporation.

Cell lines at low passage $(<4)$ were plated out into $\vec{\circ}$ 24-well plastic plates (Nunc, Gibco, Irvine, Scot- $\overrightarrow{-}$ land) at a density of $2.5 \times 10^{4}$ cells/well in $1 \mathrm{ml}$ of $\bar{\sigma}_{\mathscr{\omega}}$ DMEM+20 mM HEPES, $10 \%$ FCS, and antibiotics. The cultures were incubated at $37^{\circ} \mathrm{C}$ in a humidified atmosphere for three days to allow the $\vec{c}$ cells to become established. The medium was then removed and the cells washed three times with $\omega_{\infty}^{\omega}$ HBSS. One millilitre of medium containing $1 \% \mathrm{FCS}^{\mathrm{O}}$ was then added to each well. After a further $24^{\circ}$ hours this medium was removed and the cells $\overrightarrow{\vec{z}}$ exposed to a range of concentrations of FCS from 0 ल to $20 \%$, each concentration being used in triplicate. Twenty four hours later $5 \mu \mathrm{Ci}(185 \mathrm{kBq}) \vec{\infty}_{\infty}$ $\left[{ }^{3} \mathrm{H}\right]$ thymidine was added to each well and incuba-. $-\mathrm{V}$ tion continued for a further 24 hours.

At that time medium was removed and the cells were washed three times with HBSS and were lysed with $0.5 \mathrm{ml}$ of $19 \mathrm{M}$ formic acid. The resulting solution was transferred to labelled scintillation $\mathbb{Q}$ vials, $4.5 \mathrm{ml}$ of Optiphase 'safe' scintillant (LKB $\underset{\Rightarrow}{\stackrel{2}{\rightleftarrows}}$ Instruments, Croydon, UK) added, and the samples counted on an LKB 1218 liquid scintillation spectrometer.

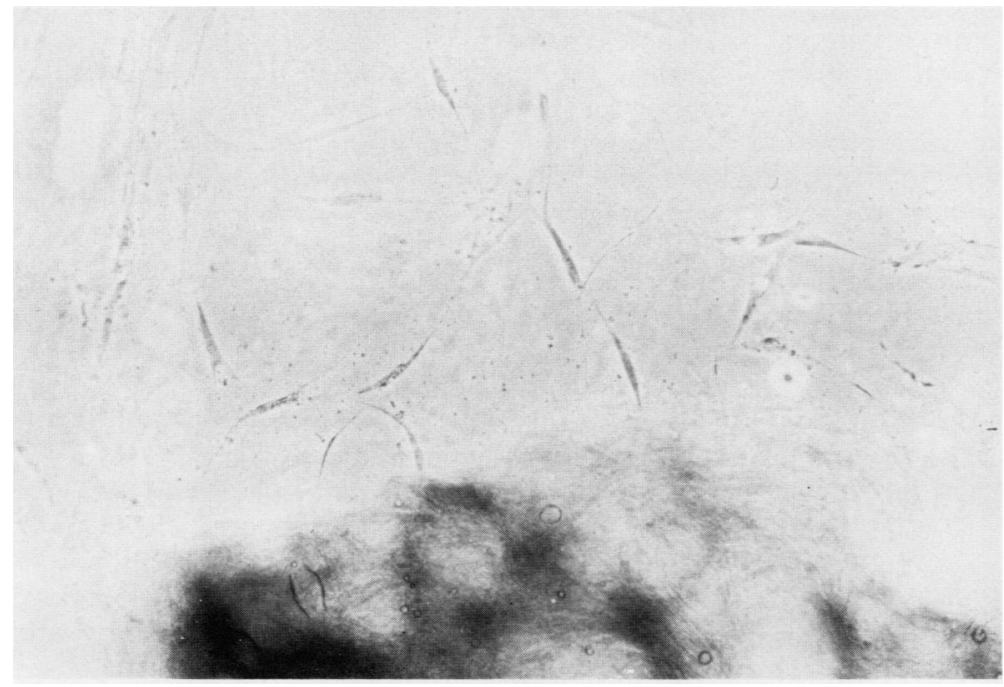

Fig. 1 Fourteen day explant culture of adult human tendon showing migration of the fibroblasts onto the surface of the culture disc. 
The mean of the triplicates for each concentration of FCS was used to construct a dose-response curve for FCS stimulated DNA synthesis for each cell line. The data were linearised by conversion to $\log$ to base 10 , and a curve was obtained by regression analysis. The slope of this curve was used as a measure of the rate of $\left[{ }^{3} \mathrm{H}\right]$ thymidine incorporation by the tendon fibroblasts, and each value was then related to the age of the donor.

In addition, comparison was made between the superficial and deep tendon fibroblast lines by comparing the mean DNA synthesis for each concentration of FCS. This was done to establish any difference between the DNA synthetic ability of superficial and deep tendon fibroblasts.

\section{Results}

IS OLATION

No visible outgrowth of cells from the explants was seen in the first two weeks after the cultures were established. After this period, however, fibroblasts started to migrate from the substance of the tendon tissue onto the surface of the Petri dish and coverslips (Fig. 1). Migration and replication then continued slowly, taking up to a further two weeks before sufficient cell numbers were present for passage (approximately $0.5 \times 10^{6}$ cells).

Successful isolation was achieved from 22 out of 27 tendons (age range 11-83 years). Once established in monolayer the cells had cell doubling times

\section{.}

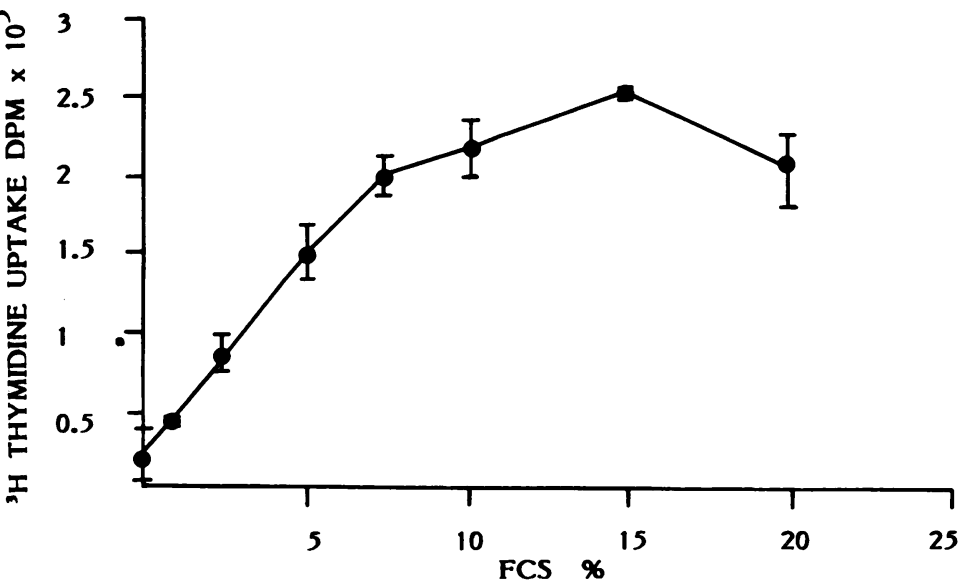

Fig. 3 Typical growth curve for a line of human tendon fibroblasts (HTB8) after stimulation with fetal calf serum (mean of triplicate cultures (SEM)).

Fig. 2 First passage tendon
fibroblasts in monolayer culture. 


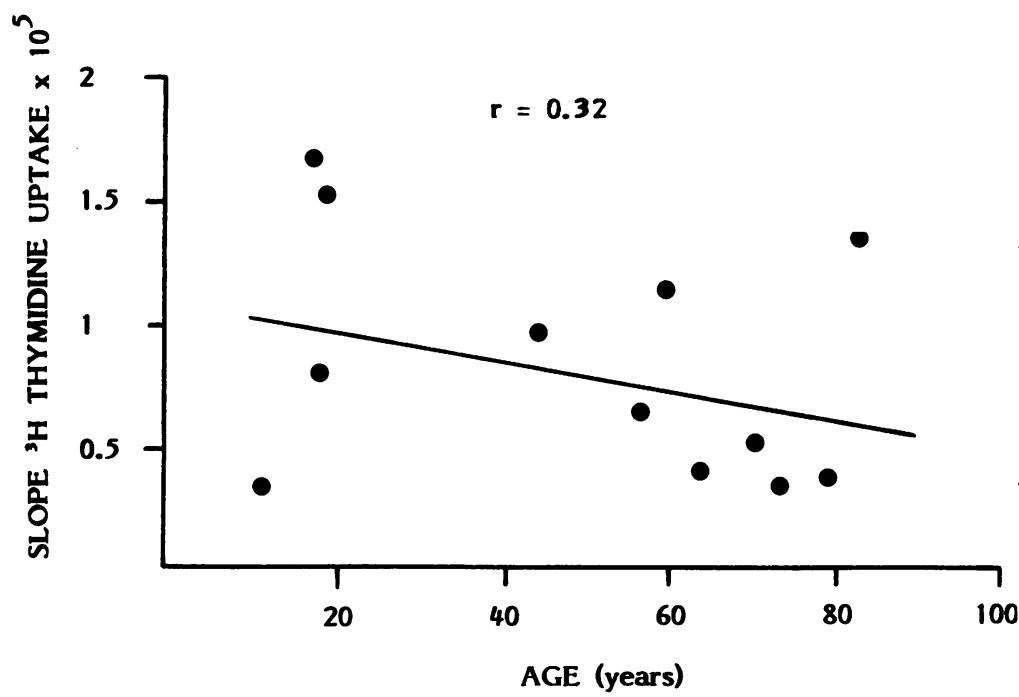

Fig. 4 The response of superficial human tendon fibroblasts (12 lines) measured by $\left[{ }^{3} \mathrm{H}\right]$ thymidine incorporation, expressed as the slope of the log linearised growth curve, derived by regression analysis, for $a$ of range of concentrations of fetal calf serum.

of between four and six days. Morphologically the cells appeared dissimilar to skin fibroblasts grown in the same conditions, being less spindle shaped and having broader cell bodies (Fig. 2).

\section{GROWTH EXPERIMENTS}

All the tendon fibroblast lines responded to induction of DNA synthesis by FCS with a progressive rise with increasing concentrations of FCS up to $15 \%$, but at $20 \%$ the serum had inhibitory effects on cell division (Fig. 3).
Variation in sensitivity to FCS was large, as thê linearised rate values show when related to the age of the donor. There was no significant reduction io the DNA synthesis with respect to age either for fibroblasts from the superficial part $(r=0.32 \%$ or from deep within the tendon $(r=0.46)$ (Figs $\frac{\$}{9}$ and 5). The mean responses of tendon fibroblasts from the superficial and deep areas of the tendon to a particular concentration of FCS were almos identical (Fig. 6).

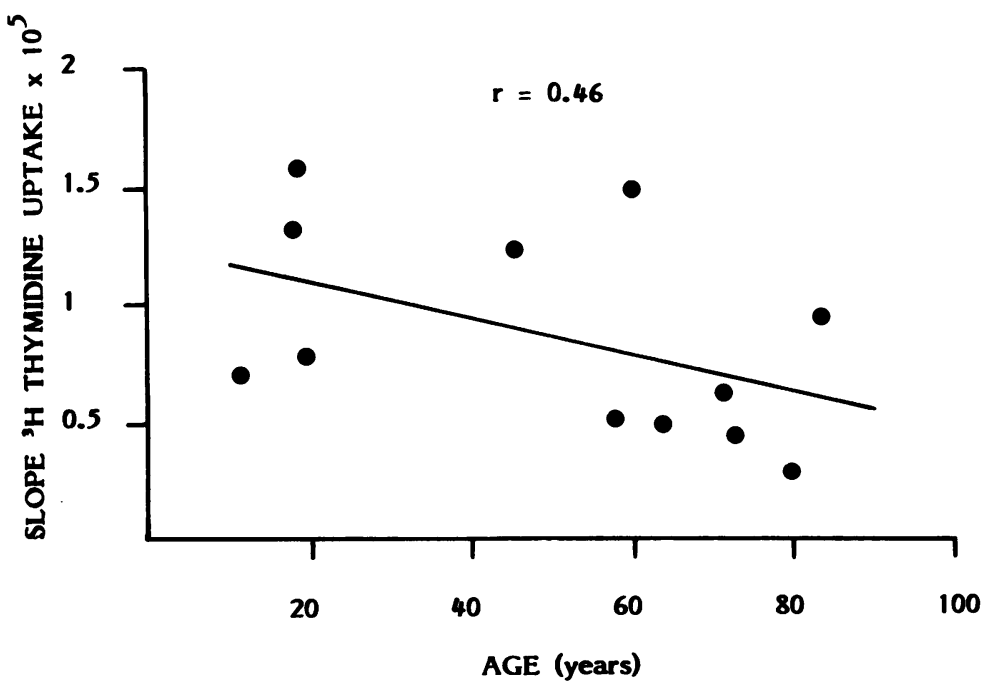

Fig. 5 The response of deep humd tendon fibroblasts (12 lines) as measured by [ $\left.{ }^{3} \mathrm{H}\right]$ thymidine incorporation, expressed as the slope of the log linearised growth curve, derived by regression analysis, for $b$ range of concentrations of fetal calf serum. 


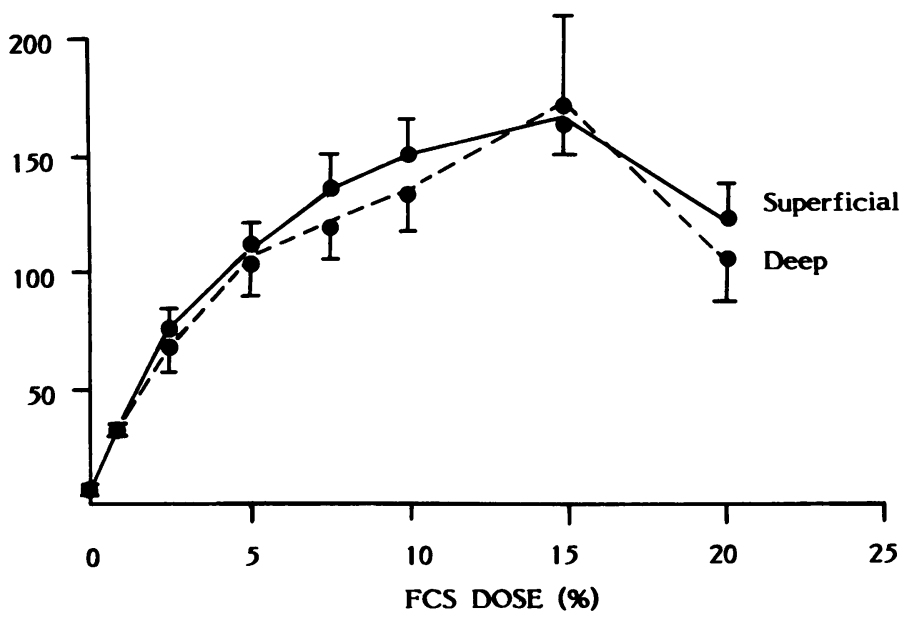

Fig. 6 Mean responses (SEM) for 12 lines of superficial and deep human tendon fibroblasts to fetal calf serum.

\section{Discussion}

It is believed that tendinous lesions such as those of the rotator cuff of the shoulder and lateral epicondylitis are at least partly due to age related tissue effects, including inadequate healing after minor repetitive injury. Whether they are only due to the effects of aging or to any genetic predisposition to poor tendon function is unknown. To determine this the characteristics of adult tendon fibroblasts in general must first be established. Although some information about their characteristics may be obtained by organ culture of tendon, ${ }^{1-4}$ such an approach has limitations as was found by Dehm and Prockop when investigating chick embryo tendon. ${ }^{5}$ This prompted them to develop a method for the isolation of the actual tendon fibroblasts.

Experiments involving gross trauma to tendon ${ }^{21}$ can only give limited insight into the way tendon fibroblasts respond to less severe injury. Also since interspecies differences probably exist, ${ }^{2} 2$ deductions about human tendon fibroblasts from this animal work are difficult. Fibroblasts from skin are not a suitable alternative to tendon fibroblasts, and fetal tendon fibroblasts may well behave differently from those of the adult.

It was thought unlikely that adult human tendon fibroblasts could be isolated as they appear to be well differentiated on microscopy ${ }^{15}$ and were thus too terminally differentiated to be able to migrate and divide. In addition, experiments on tendon healing appeared to show that tendon could only heal by adhesion ${ }^{16-19}$ when fibroblasts migrated in from surrounding tissue and not by any direct involvement of tendon fibroblasts. Studies in recent years, however, have shown that although tendon healing will occur by adhesion, primary intrinsic healing can occur and is indeed more advantageous. ${ }^{2021}$ This is of particular interest when considering the possible effects of minor repetitive trauma rather than the gross trauma of tendon severing.

In view of these reports we set out to isolate fibroblasts from adult human tendon, and, indeed, we have been able to show that it is possible to isolate fibroblasts consistently and establish and maintain them in monlayer culture.

The duration of explant culture required is likely to reflect in part the time taken for the fibroblasts to begin to replicate and partly the slow migration through the dense tendon tissue. To obtain the cells by degrading the tendon with enzymes would appear an attractive alternative, but the resistant nature of human tendon has thwarted attempts in this laboratory using methods successfully applied to animal material. ${ }^{5} 12$

In monolayer culture the cells are morphologically different in appearance from dermal fibroblasts, having a morphology closer to synovial fibroblasts. Whether the cells obtained represent all the fibroblasts in the tendon, or a particular subset which is capable of migration and replication, cannot be determined from this study. It is highly likely, however, that this population of cells is involved in the response to injury.

It has been suggested that dermal fibroblasts have a reduced ability to proliferate in vitro with increasing age of the donor, ${ }^{26}$ but a study in which the replicative life span of dermal fibroblasts was examined failed to show any age related limits. ${ }^{27}$ In the present study we have been unable to show that tendon fibroblast growth, as measured by DNA synthesis, significantly decreases with advancing age. In addition, there was no difference between 
cells derived from the superficial or deep parts of the tendon. The relation between $\left[{ }^{3} \mathrm{H}\right]$ thymidine incorporation by tendon fibroblasts and the age of the donor did show a small negative correlation, but this did not reach significance with the small sample size used in the study. Although it appears unlikely that the clinically observed high prevalence of tendinopathy in middle life is associated with any age related defect of tendon fibroblast replication, it is possible that a larger study might show such a relationship.

There may be abnormalities of tendon fibroblast replication in those patients with tendinopathy, but is is perhaps more likely that other defects of tendon fibroblast function occur, perhaps affecting collagen production and connective tissue remodelling. These defects may occur either as a consequence of the aging process or be due to genetic factors. A study is presently underway in this department of tendon material from patients undergoing surgery for chronic tendon lesions, in an attempt to investigate these aspects of tendon function.

This work was funded by Beecham Pharmaceuticals (research division) and the Arthritis and Rheumatism Council. One of us (JKW) was a Beccham research fellow. We would like to acknowledge the assistance of Professor G A Gresham. Department of Histopathology. Addenbrooke's Hospital for access to cadaveric material and Mrs J McAusland for expert secretarial help.

\section{References}

1 Manske P R, Lesker P A. Histologic evidence of intrinsic flexor tendon repair in various experimental animals: an in vitro study. Clin Orthop 1984: 182: 297-304.

2 Gelberman R H. Manske P R. Vande Berg J S, Lesker P A. Akeson $W \mathrm{H}$. Flexor tendon repair in vitro: a comparative histologic study of the rabbit, chicken, dog and monkey. J Orthop Res 1984; 2: 39-48.

3 Graham M F, Becker H. Cohen I K. Merritt W, Diegelmann R F. Intrinsic tendon fibroplasia; documentation by in vitro studies. J Orthop Res 1984: 1: 251-6.

4 Manske P R, Gelberman R H. Vande Berg J S. Lesker P A. Intrinsic flexor-tendon repair: A morphological study in vitro. J Bone Joint Surg /Am/ 1984; 66: 385-96.

5 Dehm P. Prockop D. Synthesis and extrusion of collagen by freshly isolated cells from chick embryo tendon. Biochem Biophys Acta 1971; 240: 358-69.

6 Palotie A. Effect of elevated temperature on the intracellular degradation of different collagen types. Coll Relat Res 1983; 3: 105-13.

7 Graham M F. Diegelmann R F, Cohen I K. An in vitro model of fibroplasia: simultaneous quantification of fibroblast proliferation, migration and collagen synthesis. Proc Soc Exp Biol Med 1984; 176: 302-8.
8 Taylor C M. Oelbaum R S. Grant M E. The biosynthesis 8 . glycoproteins by cultured bovine tendon fibroblasts. Connect Tissue Res 1982: 10: 319-31.

9 Tolstosher P. Haber R. Trapnell B C. Crystal R G. Procollage messenger RNA levels and activity and collagen synthests during the fetal development of sheep lung. tendon and skif J Biol Chem 1981: 256: 9672-9.

10 Webster D F. Burry H C. The effects of hypoxia on huma skin. lung and tendon cells in vitro. Br J Exp Pathol 1982: 63 $50-5$.

11 Conrad G W. Hart G W. Chen Y. Differences in vitro betweể fibroblast-like cells from cornea, heart and skin of embryon $\vec{\theta}$ chicks. J Cell Sci 1977; 26: 119-37.

12 Riederer-Henderson M A. Gauger A. Olson L. Robertson $\overrightarrow{\ddot{E}}$ Greenlec T K. Attachment and extra-cellular matrix differencos between tendon and synovial fibroblastic cells. In Vitro 1989 19: $127-33$

13 Schneider E L. Mitsui Y. Au K S. Suart Shorr S. Tissue speciffe differences in cultured human diploid fibroblasts. Exp Cell Res 1977; 108: 1-6.

14 Lemonnier F, Gautier M. Wolfrom C. Lemonnier A. Sond metabolic differences between human skin and aponeurosis fibroblasts in culture. J Cell Physiol 1980; 104: 415-23. 윽

15 Ham A W. Histology. London: Lippincott. 1974: 363-77.

16 Buck R C. Regencration of tendon. Journal of Pathology a Bacteriology 1953; 56: 1-18.

17 Potenza A D. Tendon healing within the flexor digital sheath the dog. An experimental study. J Bone Joint Surg [Am] 1963 44: $49-64$.

18 Potenza A D. Critical cvaluation of flexor-tendon healing and adhesion formation within artificial digital sheaths. J Bone Jotul Surg /Am/ 1963: 45: 1217-33.

19 Verdan C E. Half a century of flexor tendon surgery: currem status and changing philosophies. J Bone Joint Surg [Am/ 197.; 54: $472-91$.

20 Ketchum L D. Primary tendon healing: A review. J Hand Sug [Br] 1977; 2: 428-35.

21 Gelberman R H, Vande Berg J S. Lundborg G N, Akesळ $\mathrm{W} \mathrm{H}$. Flexor tendon healing and restoration of the gliding surface. An ultrastructural study in dogs. J Bone Joint Sum [Am/ 1983; 65: 70-80.

22 Becker H, Graham M F. Cohen I K. Diegelmann R F. Intrinsie tendon cell proliferation in tissue culture. $J$ Hand Surg [A 1981: 6: 616-9.

23 Manske P R, Lesker P A. Biochemical evidence of flex tendon participation in the repair process: an in vitro stuf $J$ Hand Surg $[\mathrm{Br} /$ 1984; 9: 117-20.

24 Sly W S. Grubb J. Isolation of fibroblasts from patients. In: Ce्fl culture. New York: Academic Press, 1979: 444-50. (Methods of Enzymology; Vol 58.)

25 Rank F, Eiken O, Bergenholtz A. Lundborg G, Erkel L Flexor tendon specimens in organ cultures. Scand $J$ PI Reconstr Surg 1980: 14: 179-83.

26 Rowe D W, Starman B J, Fujimoto W Y, Williams R A Abnormalities in proliferation and protein synthesis in skin fibroblasts from patients with diabetes mellitus. Diabetes 190 . 26: $284-90$.

27 Goldstein S, Moerman E J, Suart Soeldner J, Gleason R E Barnett D M. Chronologic and physiologic age affect replicatise life-span of fibroblasts from diabetic. prediabetic and noral donors. Science 1978; 199: 781-2. 